\title{
THE EFFECT OF AIRLINE PILOT CHARACTERISTICS ON PERCEPTIONS OF JOB SAFETY RISKS
}

\author{
By
}

\author{
Leon N. Moses and Ian Savage ${ }^{1}$
}

\begin{abstract}
A large cross-sectional sample of commercial airline pilots in the United States were asked for their perceptions of job safety hazards. Regression techniques are employed to investigate the relationship between these perceptions and both the length of tenure of pilots, and their specific employer within the industry. The latter is found to have a far more significant impact on risk perception. No evidence was found for a "learning curve" of job risk with respect to experience. Pilots' assessment of inadequacies in training and aircraft maintenance are found to be significantly related to the financial health of their employer.
\end{abstract}

An extensive literature has developed analyzing the effects of hazards in the workplace on labor markets. Viscusi (1979) empirically supports the theoretical hypotheses that "risky" occupations are characterized by both wage premiums to compensate for the risks, and comparatively high turnover rates. The latter observation suggests that some occupational risks only become fully apparent to workers after on-the-job experience.

This paper attempts to identify this "learning curve" using a large cross-sectional sample of U.S. commercial airline pilots. The pilots were asked for their risk perceptions on a number of potential job hazards. Regression techniques are employed to investigate the relationship between these perceptions and both the length of tenure of pilots, and their specific employer. In analyzing the inter-employer perceptions of risk, measures of firm size and financial performance are used. Therefore, the paper has a secondary objective of empirically investigating whether the characteristics of firms affect the choices they make in providing for workplace safety, in as far as it is perceived by their employees.

The latter objective is of considerable contemporary policy interest. The safety performance of the U.S. airline industry has been subject to much scrutiny in recent years. Some writers, for example Nance (1986), claim that the commercial freedom afforded to domestic airlines by the Airline Deregulation Act of 1978 has denigrated safety performance. Statistical analyses of safety outputs, i.e., accident data, do not substantiate this claim (Moses and Savage,

\footnotetext{
${ }^{1}$ Professor and Assistant Professor, respectively, of Economics and Transportation at Northwestern University, Evanston, Illinois 60208. The authors would like to thank the Aviation Research and Education Foundation, and the Air Line Pilots Association for financial support. We are glad to acknowledge Steven Albert, Julie Libera, Janelle Muntz, and Adam Rauch for their research assistance. This paper is circulated privately prior to its publication in the Journal of Risk and Uncertainty, Vol 2(4), December 1989, pp 335-351.
} 
1989). However, there is a belief that financial pressure has caused some airlines to reduce expenditures on inputs to safety such as training and maintenance. Additionally, the substantial growth in demand for air services, which has not be matched by a growth in the number of airports and provision of air traffic control services, is often cited as increasing the risk of collision. One might suspect that pilots would be a good source for information on trends in the inputs to safety production.

The conclusion of our analyses is that the characteristics of the workplace have a far more significant impact on risk perception than do years of tenure. What variations we do detect with pilot experience do not seem to be associated with the learning curve of job risk. Though, it is probable that the degree of data aggregation that we had to do, in order to produce meaningful statistical results, meant that we lost the detailed data that would reveal a learning curve.

This does not, of course, imply that learning does not occur. Indeed, the mere fact that pilots at different airlines have very different risk perceptions suggests that certain firm specific safety characteristics are observable by employees. The lack of a measurable learning curve would therefore suggest that either new employees learn very quickly, or else are familiar with the risk characteristics of individual firms prior to employment. This is quite plausible. The professional nature of the airline pilot's job, and the extensive amount of flying experience required as a private or military aviator prior to hire as a commercial pilot, may mean that new recruits are well informed on safety risks, and the reputation of individual firms

The leading contemporary job hazards cited by pilots are: midair collision between aircraft, deficient training, and declining airworthiness of aircraft. With regard to the former risk, our analysis reveals that the State of California is viewed as particularly risky. The large number of small private aircraft movements in that state may be the explanation. Dissatisfaction with training and maintenance are significantly related to the financial health of the employing airline. This finding appears to conflict with Golbe $(1986)$ and Rose $(1988,1989)$ who were unable to find clear, consistent links between airline profitability and accident rates. Explanations for the apparent differences could range from surmising that pilots were less than honest in their responses in the survey, to questioning the specification of a safety production function which describes how safety inputs (training, maintenance etc.) are transformed into actual safety performance.

\section{THEORY AND LITERATURE REVIEW}

New hires are unlikely to be as well informed on workplace hazards as they are with regard to, say, wages and hours of work. With increasing tenure, employees should be able to better assess risk due to a combination of two factors: (1) they are better able to understand how a firm's training and maintenance procedures affect the probability of accidents; and (2) they become more knowledgeable about the actual occurrence and severity of industrial accidents. The latter is an especially good example of Bayesian learning.

The empirical literature concerning the learning curve which describes the speed with which new employees assimilate job hazard probabilities is not extensive and is imperfect. 
Ideally one would wish to have a panel survey, tracking over time individual employee's perceptions of the degree of risk they are exposed to. In the absence of such data, the best alternative is a cross-sectional database of workers of varying experience who undertake similar jobs. A dataset of this type was collected in the chemical industry by Viscusi and O'Connor (1987). Employees of known age, sex, education, and marital status were asked to indicate on a linear scale the degree of risk they perceived as being associated with their jobs. A number of hypotheses were investigated using this dataset, including the impacts of introducing a new hazard into the workplace. However, Viscusi and O'Connor do not explicitly report whether more experienced workers indicate a higher perception of risk than new recruits to the same job.

Our dataset is also of a cross-sectional nature involving pilots with varying lengths of tenure at almost all the major scheduled airlines in the United States. This obviously presents an analytical problem as the risks inherent in the workplace vary depending on the type of operation the pilot is flying, the type of aircraft, and the airline company the pilot works for. The use of cross-sectional data to estimate a learning curve requires a correction for this variation. Section 4 of this paper describes the variables we introduce to take account of this problem. Another frequently encountered problem is that more senior employees are assigned less odious and safer tasks than new employees, even though the actual "job" may be the same. This is not the case with our data. Cockpit crews consist of, in descending order of seniority: a captain, a first officer and, in the case of certain aircraft, a second officer. All ranks are exposed to exactly the same job safety hazards.

The format of the paper is as follows: section 2 describes the dataset; section 3 outlines the methods by which we decided on the specific potential job hazards to analyze; section 4 discusses the analytical techniques and explanatory variables used; the four leading hazards are analyzed in sections 5 - 8; and sections 9 and 10 contain our concluding comments.

\section{THE DATASET}

Our data were drawn from a 110 question survey on various contemporary aspects of air safety. The questionnaire ranged over many different areas of contemporary aviation issues including: air traffic congestion; human performance factors; training; runway lighting; security; aircraft maintenance; and cockpit automation. Some questions dealt with broad matters of opinion, others were detailed factual or attitudinal questions on specific aircraft components, documentation or procedures.

Since the safety of airline operation is intimately associated with the safety of the cockpit crew, responses to the questionnaire implicitly indicate pilots' perceptions of personal job risk. The survey was sponsored by the Air Line Pilots Association (ALPA) and conducted by a leading market research firm in June 1986. The population for this survey is particularly comprehensive as ALPA's 28,000 members represent $85 \%$ of pilots flying large commercial aircraft, and the majority of those flying for commuter airlines ${ }^{2}$, in the United States. The response rate to the mail-in survey was high at $35 \%$. Our dataset consisted of a sub-sample of

\footnotetext{
${ }^{2} \mathrm{~A}$ commuter airline is one operating aircraft, typically turbo-props, with less than 30 seats.
} 
1474 questionnaire responses for which we knew the following characteristics of the respondent: rank, employer, aircraft type currently flown, age, and years of service.

A brief review of the survey findings will help provide the context in which to interpret our analysis. The aggregate results, reported in Fingerhut (1986), indicated considerable concern about contemporary air safety. An indication of the strength of the concern is that half of those surveyed felt that economic deregulation had greatly affected safety, with almost all respondents acknowledging there had been some impact. In attributing the cause of this decline, nearly $70 \%$ felt that financial pressure on airlines was partly to blame, $40 \%$ felt inexperienced managers were partly the cause, and $60 \%$ said that Federal Government through its agency the Federal Aviation Administration (FAA) was partly responsible.

There is support for the financial pressure argument elsewhere in the questionnaire. Ten percent of pilots said they were frequently pressured into flying aircraft in contravention of the "Minimum Equipment List", which specifies combinations of on-board equipment that can be inoperative without grounding the plane. Another $40 \%$ said that they were sometimes pressured. About half the pilots felt that the aircraft they flew had an excessive number of components whose maintenance had been deferred, with the same proportion believing that the airworthiness of their aircraft had declined since deregulation.

Pilots also felt that the government had failed to provide adequate airport capacity and modern air traffic control monitoring equipment, to meet the increase in aircraft movements that followed deregulation. $40 \%$ of respondents indicated that their greatest safety concerns were collisions between aircraft due to congestion and the inadequacies of air traffic control systems. They mentioned these factors over ten times more frequently than they mentioned weather related concerns such as wind shear, or terrorist incidents.

\section{SELECTION OF LEADING HAZARDS}

The questionnaire ranged over many different potential job risks. For the purpose of meaningful and interesting analysis we wished to identify those hazards for which there was variation in opinion between pilots, and which pilots regarded as being of the greatest contemporary importance. The first of these objectives was achieved by testing the relationship between various pilot characteristics and individual questions using Chi-square techniques. As a result of this filtering, we were able to define a small number of questions which displayed considerable systematic variation in response. The selection of the leading contemporary hazards for detailed analysis was accomplished by regressing pilots' responses to the specific areas of concern on their opinion as to whether deregulation had affected safety: This latter question being the one that best gauged a pilot's view of contemporary air safety.

Our dependent variable was the response to the question: Do you think that airline safety has been adversely affected by deregulation. In the aggregate, $54 \%$ of our sample answered "greatly", 44\% answered "somewhat", and only 2\% said there had been no effect, were not sure, or did not mark an answer. We used a dummy variable taking the value 1 if the response was "greatly". 
The explanatory variables were responses to the following questions and issues: did the pilot view delays as a serious problem; had the pilot experienced a near midair collision; had the pilot experienced a "runway incursion", a near collision on the ground; did the pilot feel that initial training was inadequate; had the pilot experienced problems with inexperienced new crew members; did the pilot feel carry-on baggage was a serious safety hazard; did the pilot believe captains at their line were pressured into accepting aircraft with excessive deferred maintenance; did the pilot believe that airworthiness had declined; and did the pilot feel that deicing was unsatisfactory. All of these variables were of a $0-1$ form, with the value 1 being assigned if the respondent felt that a problem existed.

Statistically significant positive coefficients would indicate that the respondents recognize that a problem exists and that this problem increases occupational risk. It is possible that more experienced pilots may be both more aware of problem areas, and more able to appraise whether these problems expose them to more risk. To ensure that we were observing a priority listing of hazards rather than the learning curve, we introduced explanatory variables for pilot experience. Commercial pilots are graded into three ranks: captain, first officer, and second officer. We used dummy variables for captain and first officer to represent this seniority. We acknowledge that this represents a shift variable rather than altering the slope of the relationship between the dependent variable and the potential areas of concern. The reader is reminded that our concern at this stage is just to identify the leading hazards, and that the relationship between rank and various job hazards is explicitly addressed later in the paper.

The results are presented in Table 1 . The issues that seem strongly to affect a pilot's view of safety are primarily maintenance declines, training inadequacies, and inexperienced new hires; followed by excessive carry-on baggage and delays. The other variables were not significantly different from zero. It is interesting to note that while pilots consider the risks of midair collision to be their greatest safety fear, they do not appear to associate this risk with the impacts of deregulation. In this equation captains and first officers have significantly less strong views on deregulation's effect on safety than second officers. This might suggest that a negatively sloped learning curve exists in which senior employees believe the job is less risky than do the newer hires. We return to study this issue in greater detail in section 5.

Unfortunately the equation only explains $9 \%$ of pilots' opinions. Our initial reaction was to deploy logit and probit techniques to cure problems frequently encountered with 0 - 1 dependent variables. Neither technique improved the explanatory power or altered our conclusion as to which variables were significant. Our real problem is one that is common to most opinion research surveys, and occurs because people vary in their interpretation of questions. The most popular answers to the question that forms the dependent variable were "somewhat" or "greatly". Two people may have similar views yet interpret the words "somewhat" and "greatly" in different ways and therefore give different answers. In addition, there may be a great variation in responses to a given question even among pilots of similar experience and factual knowledge about a job hazard. Some pilots might feel more troubled about a given factual condition while others are not upset and give different answers.

In conducting this analysis we were conscious of one potential econometric problem. Our Chi-square analysis indicated to us that certain airlines were consistently viewed unfavorably by 
their pilots on all issues, and other airlines were consistently viewed favorably. As a result, serious multicollinearity could result. However our tests indicated that while this was certainly a problem if pilots were grouped on the basis of their employer, this consistency of response was not evident when looking at individual pilots.

\section{ANALYTICAL TECHNIQUES AND VARIABLES EMPLOYED}

\subsection{Data Preparation}

The low explanatory power of the regression reported in the previous section suggested that we were likely to have econometric problems. There were few places in the questionnaire where even pilots of similar seniority at the same airline had unanimous views. This variation in response meant any regression analysis would have poor explanatory power. Test regressions we conducted on the relationship between pilot characteristics and the leading job risks found this to be the case, even when logit and probit techniques were employed. Indeed the variation was so great that we could not discern any statistically significant relationships.

The solution commonly adopted is to collect the respondents into groups and conduct the analysis in terms of the mean opinions of these groups. This averaging reduces the variability. The groups we chose preserved the pilot characteristics we required to identify a learning curve, and correct for the variation in risk between workplaces in our cross-sectional sample. We therefore grouped pilots into the airlines they worked for, and then sub-divided the respondents in each airline up by rank. Thirteen large airlines were identified individually ${ }^{3}$. Two additional groups -other jet carriers ${ }^{4}$, and commuter airlines ${ }^{5}$ - were formed to accommodate smaller airlines. The maximum number of groups we could have is therefore 45 . In practice we found no second officers in five of the airline groups. We therefore had 40 points with which to estimate our regression lines. Obviously some of these groupings (e.g., captains at Delta Air Lines) have many more pilots in them than others (e,g., second officers at Air California). Therefore we weighted the groups by the number of pilots in that group.

\subsection{Dependent Variables}

We decided to focus on four areas of job risk perception. The first is the pilots' overall view of contemporary air safety using the deregulation's effect on the safety variable employed previously. The other three are the leading specific hazards identified in section 3: training,

\footnotetext{
${ }^{3}$ Air California, Delta Air Lines, Eastern Air Lines, Flying Tiger Line, Northwest Orient Airlines, Pacific Southwest Airlines, Pan American World Airways, Piedmont Aviation, Republic Airlines, Trans World Airlines, United Air Lines, USAir, and Western Air Lines.

${ }^{4}$ Alaska Airlines, Aloha Airlines, Air Atlanta, Braniff Airways, Frontier Airlines, Hawaiian Air, Midway Airlines, Ozark Air Lines, and Transamerica Airlines.

${ }^{5}$ Air Wisconsin, Aspen Airways, Avair, Brockway Air, Comair, Henson Airlines, Pocono Airlines, Precision Airlines, Ross Aviation, Royale Airlines, Simmons Airlines, and Suburban Airlines.
} 
airworthiness, and near midair collisions. The nature of these variables is discussed in greater detail when each is analyzed in sections 5 through 8.

\subsection{Explanatory Variables: The Learning Curve}

We used the pilot's rank as our primary measure of job experience. As explained above two dummy variables were used to indicate which of the three ranks our pilot group represents. In general the years of tenure represented by each rank is remarkably similar at most airlines. However to take account of the minor differences that do exist, principally between jet and commuter carriers, the average years of service of the pilot group was included as a variable. A significant coefficient on this latter variable should therefore be interpreted as being more related to the difference in risk between commuter and jet airlines rather than being associated with the learning curve.

\subsection{Explanatory Variables: Correcting for Varying Workplaces}

The next group of variables correct our regressions for the variety of workplaces in our cross-sectional sample. The workplace varies depending on the type of operation the pilot is flying, the type of aircraft, and the airline the pilot works for. Where risk varies between workplaces, failure to account for this variation will lead to imprecision and poor explanatory power of any estimate of the learning curve. Additionally, observation of the characteristics of workplaces viewed as relatively risky is of interest in its own right.

The influence of individual employers could be represented by a series of dummy variables. Even ignoring the fact that our small sample size effectively rules out such a dummy variable structure, we felt it to be more instructive to use descriptive variables of the employer. On an a priori basis one would imagine that the best variable to use for the difference in risk between airlines is the ex-post job risk. This we measured by the accident rate of the employing airline, measured as the number of accidents and incidents per million departures in the period immediately prior to the survey $(1982-85)^{6}$. The average rate was 10.1 with a range from 0 to 19.2. A possible objection is that we are using the actual accident rate to explain pilots' perceptions on issues such as training and maintenance, which themselves should explain the safety performance of the airline. If there were clear simultaneous equation biases present we would have to deploy more sophisticated econometric techniques than Ordinary Least Squares. However, the reported perceptions about the adequacy of the various inputs to safety are not reflected in the actual safety performance of the various airlines. This curious fact is discussed at more length in section 9.

Given that ex-post risk and risk perception are not highly related, we had to look for other descriptive variables to help correct the variations across airlines. Two additional variables were used: financial health and size. The first of these was included because many students of the

\footnotetext{
${ }^{6} \mathrm{An}$ "accident" is when a person suffers death or serious injury and/or the aircraft receives substantial damage. "Incidents" are less serious occurrences "in which a hazard or potential hazard to safety is involved". The use of departures in the denominator of the accident rate reflects the fact that nearly all accidents occur during the take-off or landing stages of flight.
} 
industry believe that financially stressed airlines are more likely to engage in unsafe practices, e.g., inadequate maintenance and improper training. For financial status a variable was employed that represented the number of years the airline suffered a loss in the period 1980-85. The average period of loss was 2.6 years with a range from 0 to 5 . A priori one might expect there to be strong collinearity between the accident rate and the financial performance of an airline. However, we found a correlation coefficient of only 0.37 , and this is supported by previous research by Golbe (1986) and Rose $(1988,1989)$ who were unable to determine a clear consistent link between profits and accidents in this industry.

The size variable was measured by the number of pilots employed. It measures economies or diseconomies of scale in perceived safety provision. Beyond a certain size, pilots may feel that it is difficult for an airline to manage safety adequately. The average airline size was 774 pilots with a range from 64 to 4464 .

The type of operation, and by implication the equipment flown, falls into three broad categories. The first is long haul international or trans-continental operation. This is characterized by relatively few take-offs and landings. Statistically most accidents occur during the take-off and landing and associated ascent and decent stages of flight. Therefore pilots flying long haul operations should have a lower perception of certain types of job risk. We measured long haul operation by a variable representing the proportion of wide body aircraft at each airline, these being the type of aircraft deployed on such flights ${ }^{7}$. The second is the ordinary jetoperated short haul operations. The third is commuter operation characterized by relatively numerous take-offs and landings, use of smaller turbo-propeller aircraft, low altitude flight, and use of lower quality airports. One would expect this type of operation to be regarded as relatively risky. Legal classification in the United States means that there is a one-to-one mapping of commuter operations and the companies that form our commuter airline grouping.

\subsection{Regression Form}

Ordinary Least Squares techniques were used on a dataset of 40 pilot groups, each group being weighted by the number of pilots in that group. The explanatory variables are a linear combination of the learning curve dummy variables and the variables correcting for interworkplace effects. One might argue that the relationship between the experience and workplace variables is multiplicative rather than additive. Testing of such a multiplicative relationship would entail Chow (1960) tests or the use of slope dummy variables. The grouping of data described above produced sample sizes too small to effectively support such analyses.

\section{DEREGULATION'S EFFECT ON SAFETY}

The first risk perception question we analyzed was the response to the question: Do you think that airline safety has been adversely affected by deregulation. In our analysis we

\footnotetext{
${ }^{7}$ Airbus Industrie 300, 310; Boeing 747, 767; McDonnell Douglas DC10; Lockheed L1011. A mean proportion of the fleet of each airline of $17.2 \%$ with a range $0 \%$ to $64 \%$.
} 
calculated the percentage of pilots in each group whose response was "greatly", which was the opinion of $54 \%$ of the respondents overall.

The regression results are presented in Table 2. They reveal that the promising negative relationship between experience and risk perception observed in Section 3 becomes insignificant when correction is made for differing characteristics of the workplace. By contrast workplace characteristics (financial status, the actual accident rate, and carrier size) have statistically significant influences on how the pilots answered the question. An increase by one in the number of years of financial loss for an airline in the period 1980-85 results in a 2.7 percentage point increase in the perception by its employees that deregulation has greatly affected safety. Pilots at large airlines have a greater propensity to view deregulation as having a great effect on safety (a 3.3 percentage point increase for each 1000 pilots employed); as do pilots at airlines with inferior safety records (a one percentage point increase for each accident/incident per million departures).

The regression was found to explain $41 \%$ of the variation in answers between pilot groups. It should there be borne in mind that the actual variation in answers is greatly influenced by other, unidentified, factors as well. Nevertheless we have managed to identify important factors that influence about half of the variation in pilots' opinion.

\section{INITIAL TRAINING}

Similar variables were employed in the analysis of the question: Do you think your airline's training program is adequate in initial training? In aggregate terms $29 \%$ of respondents felt their initial training was inadequate, $63 \%$ judged it adequate, $6 \%$ were not sure, and only $1 \%$ failed to mark an answer. For analytical purposes we calculated the percentage of pilots in each group that felt their initial training was inadequate. The questionnaire also made similar enquiries about recurrent and promotion related training. Consistent answers were generally given by pilots to all three questions, so we chose only this one for detailed analysis.

The results of the analysis are presented in Table 3. Our results indicate that the difference in opinion between first and second officers is statistically insignificant. However, captains are much less satisfied than the other ranks. Perhaps they compare unfavorably the training received by the younger pilots with whom they work, and the training they received when they started. An alternative explanation is that the greater experience of captains permits them to better evaluate the training they received.

Again the inter-workplace variables have strong effects. Pilots at smaller jet airlines are more satisfied with their training. Dissatisfaction increases by 7.7 percentage points for each 1000 pilots employed. This is not the case at commuter airlines. As we have already explained, the years of service variable primarily picks up these airlines. There is a very strong relationship indicating that the pilots at these airlines are relatively dissatisfied with training. Financial difficulties at an airline are strongly associated with an increase in the dissatisfaction with training. A one-year increase in the number of years of losses in the period 1980-5 leads to a 5.5 percentage point increase in dissatisfaction. The accident experience of the employing airline is not significantly associated with dissatisfaction with training. 
Overall this equation explains 64\% of the variation in opinions of pilot groups. In other words the variables we are using explain the majority of the things that influence variations in pilots' opinions.

\section{AIRWORTHINESS}

Pilots were asked: In your opinion, have you seen a decline in the maintenance/airworthiness level of your aircraft? Overall $49 \%$ said this was the case, $43 \%$ disagreed, $7 \%$ were not sure, and again only $1 \%$ failed to mark an answer. For analytical purposes we calculated the percentage of pilots in each group who said that it had.

The results, using the same variables as before, are reported in Table 4. No learning curve effect can be established. Increased experienced does not seem to improve judgment of aircraft condition. In contrast there is an exceedingly strong relationship between airworthiness and the financial status of the employing airline. An increase by one year in the number of years of losses in the period 1980-5 leads to a 12 percentage point rise in the probability that a group of pilots believe that airworthiness has declined. An increase in accident rate was also found to have a significant influence on opinions concerning airworthiness: A one percentage point increase for each accident/incident per million departures. The equation explains $75 \%$ of the variations in pilots' responses. Therefore not only does financial status of an airline influence pilots' opinions on airworthiness, it also explains most of the variation in their responses to this question.

\section{NEAR MIDAIR COLLISIONS}

Pilots opinions were solicited on the statement: The near midair collision (NMAC) problem is not as severe as is widely believed and ALPA should direct its resources to other problem areas. $70 \%$ disagreed with the statement, i.e., they felt NMACs are a serious problem, $15 \%$ agreed, $14 \%$ were not sure, and 1\% did not answer. We used the percentage of pilots in each group who felt the problem was severe as our dependent variable.

It will be noted that the question is quite misleading. It is confusingly worded in that it contains a double negative, and also two questions rolled into one i.e., is the near midair collision problem serious, and should ALPA redirect its resources elsewhere. However given that nearly half of the respondents listed air traffic control deficiencies as their greatest single safety fear we can be more confident in believing that $70 \%$ of pilots feel that the threat of near midair collisions is severe.

We initially tested the responses to this question using the same variables as were used for the issues above. However, we found that they did not explain the opinions of pilots on this issue. They explained only $7 \%$ of the responses. In addition, none of the variables were statistically significant. In other words a learning curve, or the size and financial status of the employer do not influence the perception of NMACs. This result is not too surprising. 
We therefore adopted a different approach to see if other characteristics of the workplace such as the type and geographical area of operation influenced responses. In section 4 we indicated that there is a difference in exposure to NMACs between pilots of long haul jet, short haul jet, and commuter operations. We represented these different types of operation in two ways. First, a dummy variable taking the value 1 for our commuter airline pilot groups. Second, a variable measuring the proportion of wide body aircraft in an airline's fleet which was our proxy for the extent of long haul operation. The type of aircraft entered in other ways as well. We calculated two fleet proportions for each airline: automated aircraft ${ }^{8}$, and aircraft with two rather than three person cockpits ${ }^{9}$. It is commonly believed that automated planes require pilots to have their eyes focused on computer displays in the cockpit rather than scanning the sky ahead for intruding aircraft. Similarly the elimination of the third crew member reduces the number of pairs of eyes available for this purpose. Finally, at the suggestion of the pilots union, we tested whether pilots of the Boeing 737 (B737) ${ }^{10}$ or McDonnell Douglas DC9/MD80 ${ }^{11}$ craft viewed the problem more seriously because these planes are regarded as having particularly bad visibility from the cockpit.

Additionally, our Chi-square analysis alerted us to the higher awareness of NMACs among pilots of airlines which are relatively specialized in providing service in California. We calculated the proportion of pilots in each airline who were based in California and used this as a variable (a mean value of $15 \%$ with a range of $0 \%$ to $100 \%$ ). This information was obtained from ALPA membership records.

The results are reported in Table 5. The proportion of Californian pilots is the strongest variable, indicating that California is perceived as an area where there is a higher possibility of NMACs compared to other parts of the world. Each $10 \%$ of an airline's workforce that is based in California results in a 1.8 percentage point increase in the concern about NMACs, a result that we comment further on in section 10. The next strongest effect is the proportion of wide bodied jets in an airline's fleet. This suggests pilots of long haul flights, perhaps operating internationally, are less concerned about the midair collision problem. The proportion of pilots at an airline concerned about NMACs declines by 4.1 percentage points for each $10 \%$ of that airline's fleet which is wide bodied. All the other variables are not significantly different from zero. Therefore we cannot conclude that the opinions of commuter pilots, pilots in two-person cockpits, pilots of automated planes or pilots of B737 or DC9/MD80 differ from pilots in general. Indeed, with the exception of commuter pilots, the directions of the estimated (insignificant) differences are of a counter-intuitive nature.

\footnotetext{
${ }^{8}$ Airbus Industrie 310; Boeing 737-300, 757, 767; McDonnell Douglas MD80. A mean fleet proportion of 10.6\% with a range $0 \%$ to $54 \%$.

${ }^{9}$ The aircraft with three person cockpits are: Airbus Industrie 300, Boeing 727, 747; McDonnell Douglas DC8, DC10; Lockheed L188, L1011. The proportion of two person cockpits per airline averages 53\% with a range $0 \%$ to $100 \%$.

${ }^{10}$ Mean proportion per airline of $14.3 \%$ with range $0 \%$ to $100 \%$.

${ }^{11}$ Mean proportion per airline of $19.0 \%$ with range $0 \%$ to $100 \%$.
} 
The equation was only found to explain $17 \%$ of the pilots' responses. This indicates that we have not yet been able to identify the major factors that influence variations in pilots' opinions on the threat of midair collisions.

\section{DISCUSSION}

\subsection{The Issue of Biased Response}

The results in this paper are based on the stated perceptions of a group of people who, while intimately familiar with safety issues, might have had "political" reasons to falsely represent their views. Pilots may have a particular dislike of deregulation. Working conditions of ALPA members have declined in quality since deregulation, salaries have increased at a lower rate, and new hires are often on a reduced pay scale. Non-union carriers have entered the industry, and some existing carriers are no longer staffed by ALPA pilots.

One could argue that pilots would, from a standpoint of public opinion, wish to discredit deregulation on the grounds of safety. Providing the bias is held by all pilots then our comparisons of different subgroups of the pilot population should still be valid. However, one could argue that bad labor relations at individual carriers could influence pilots to falsely represent the safety of that airline. Given that recent labor unrest has been associated with management attempts to extract wage concessions in the face of poor financial performance, misleading econometric results could emerge. It is certainly true that two large airlines which have recently experienced bitter labor relations difficulties fare badly in the survey. However, another large airline whose history is marked by labor-management unrest is the most favorably regarded by its employees in this questionnaire.

\subsection{Perception versus "Reality"}

It is instructive to compare the perceptions of the inputs to safety at the various airlines with actual safety performance. Our findings of a strong link between a carrier's financial status and the perception of pilots of the adequacy of its inputs to the safety production process appear to conflict with other academic research. Rose $(1988,1989)$ has conducted statistical investigations, involving data for 30 years, relating financial conditions and accident experience. Her analysis suggests that the evidence for such a relationship is very slim and confined to the smaller carriers. This contrasts with our findings which indicate that pilots believe that the link between financial condition and measures of safety is especially strong among the nation's largest carriers. Also the deregulation-safety linkage claimed by pilots in the questionnaire has not been borne out by analysis of actual safety performance (Moses and Savage, 1989).

Explanations for the apparent differences could range from surmising that pilots were less than honest in their responses, to questioning the specification of a safety production function which describes how safety inputs (training, maintenance and so on) are transformed into actual safety performance. Authors such as Nance (1986) have argued that declines in the inputs to safety without a decline in the output are perfectly feasible. These authors view safety as being partly a type of stock variable in which airlines invested more freely in the past than they have 
done since deregulation. The investment includes such things as the hiring of highly qualified personnel, extensive programs of initial and lifetime training of personnel, careful maintenance of aircraft, timely replacement of aircraft, development of state-of-the-art maintenance bases with large inventories of parts, and so on. It is claimed that in the past airlines did more than they were required to do by the FAA, and a stock of safety was built up that still provide protection against increases in accident rates. It is thus argued by these authors that ex-post accident figures are not very useful as an ex-ante predictor of future accident trends. Support for these views has recently come from government. The FAA has commissioned a five year program to recommend a series of "leading safety indicators" for use in oversight of the industry.

\section{CONCLUSIONS}

\subsection{Workplace Characteristics Regarded as being Relatively Risky}

Pilots' greatest safety fear is associated with near midair collisions and inadequacies in the air traffic control system. Their fear is not associated with their tenure or the corporate nature of their employer. Rather, it is associated with the geographic area and type of operations which they fly. Pilots of long haul flights with extensive high altitude flying and relatively few take-offs and landings are, understandably, less concerned about near midair collisions. The geographic area of concern is the State of California. This finding is worthy of more discussion, because this is not the area popularly regarded as being the most congested. According to pilots that dubious honor belongs to Miami, Atlanta, Chicago and New York. It is our belief that this finding reflects the large amount of private aircraft movements in California. Until recently, these aircraft could fly in the vicinity of commercial airports without "mode $\mathrm{C}$ " transponders, devices that permit height as well as latitude and longitude to be recorded on radar. Without such information air traffic controllers cannot determine whether a dangerously close situation is developing, and warn the pilots accordingly.

Virtually all pilots felt that deregulation has resulted in some adverse effect on safety. Half of the respondents view the effect as being "great". Our analysis identifies training and maintenance dissatisfactions as being significantly related to pilots' concerns about deregulationsafety linkages. Dissatisfaction with training and maintenance are themselves significantly related to the financial health of the employing airline. This relationship is particularly marked in the case of concerns over declining airworthiness. A somewhat surprising result is that pilots at smaller airlines view the adequacy of their training more favorably than pilots at large airlines. Perhaps there are diseconomies of scale in the training of jet airline pilots.

\subsection{Existence of a Learning Curve}

Our primary conclusion is that the characteristics of the workplace have a far more significant impact on risk perception than does tenure. What variations we do detect with pilot experience, for example on the issue of adequacy of training, do not seem to be associated with a learning curve for job risk. It is probable that the degree of aggregation of pilots into groups, that we had to do in order to produce meaningful statistical results, means that we lost the detailed data that would expose any learning curve. 
This does not, of course, imply that learning does not occur. Indeed, the mere fact that pilots at different airlines have very different risk perceptions suggests that certain firm specific safety characteristics are observable by employees. The lack of a measurable learning curve would therefore suggest that either new employees learn very quickly, or else are familiar with the risk characteristics of both the occupation in general, and individual firms in particular, prior to employment. This is quite plausible. The professional nature of the airline pilot's job, and the extensive amount of flying experience required as a private or military aviator prior to hire as a commercial pilot, may mean that new recruits are well informed on safety risks, and the reputation of individual firms.

\section{$\underline{\text { REFERENCES }}$}

Chow, Gregory. (1960). "Tests of Equality between Sets of Regressions," Econometrica 28, 591605.

Fingerhut, Vic. (1986). "The Pilots View of Air Safety," Air Line Pilot 55, 17-22.

Golbe, Devra. (1986). "Safety and Profits in the Airline Industry," Journal of Industrial Economics 34, 305-318.

Moses, Leon and Ian Savage (eds.). (1989). Transportation Safety in an Age of Deregulation. New York: Oxford University Press.

Nance, John. (1986). Blind Trust. New York: William Morrow.

Rose, Nancy. (1988). "Profitability and Product Quality: Economic Determinants of Airline Safety Performance" (Working Paper 2032-88.) Sloan School of Management, Massachusetts Institute of Technology.

Rose, Nancy. (1989). "Financial Influences on Airline Safety." In Leon Moses and Ian Savage (eds.), Transportation Safety in an Age of Deregulation. New York: Oxford University Press.

Viscusi, W. Kip. (1979). Employment Hazards: An Investigation of Market Performance. Cambridge, Mass: Harvard University Press.

Viscusi, W. Kip and Charles O'Connor. (1987). "Hazard Warnings for Workplace Risks: Effects on Risk Perceptions, Wage Rates, and Turnover." In W. Kip Viscusi and Wesley Magat (eds.), Learning about Risk: Consumer and Worker Responses to Hazard Information. Cambridge, Mass: Harvard University Press. 
TABLE 1. Regression Results on Dummy Variable: Pilot Believes Airline Safety Has Been Greatly Affected By Deregulation

\begin{tabular}{|l|c|}
\hline Explanatory Variable & Coefficient (Standard Error) \\
\hline Constant & $0.47(0.07)$ \\
\hline Learning Curve Dummy Variables & $-0.14(0.07)$ \\
\hline Captain & $-0.19(0.07)$ \\
\hline First Officer & $0.17(0.03)$ \\
\hline Workplace Hazard Dummy Variables & $0.10(0.03)$ \\
\hline Pilot believes maintenance/airworthiness has declined & $0.08(0.03)$ \\
\hline Pilot believes initial training is inadequate & $0.08(0.03)$ \\
\hline Pilot believes excess carry-on baggage is a serious safety hazard & $0.06(0.03)$ \\
\hline Pilot has experienced problems with inexperienced new hires & $0.05(0.04)$ \\
\hline Pilot views delays as a serious problem & $0.03(0.03)$ \\
\hline Pilot feels deicing is unsatisfactory & $-0.02(0.03)$ \\
\hline $\begin{array}{l}\text { Pilot believes that captains at their line are pressured into } \\
\text { accepting aircraft with excessive deferred (maintenance) items }\end{array}$ & $-0.05(0.03)$ \\
\hline Pilot has experienced a runway incursion & $0.01(0.03)$ \\
\hline Pilot has experienced a near midair collision & 1,284 \\
\hline Pilot has experienced more than one near midair collision & 0.09 \\
\hline N & \\
\hline Corrected R & \\
\hline
\end{tabular}


TABLE 2: Regression Results on the Percentage of Pilots in Each Group Who Believe That Airline Safety Has Been Greatly Affected By Deregulation

\begin{tabular}{|l|c|}
\hline Explanatory Variable & Coefficient (Standard Error) \\
\hline Constant & 42.88 ( 9.12) \\
\hline Learning Curve Dummy Variables & $-5.47(10.05)$ \\
\hline Captain & -11.89 ( 8.35) \\
\hline First Officer & $0.96(0.44)$ \\
\hline Inter-Employer Variation & 2.65 ( 1.13) \\
\hline Accidents/incidents per million departures & $3.27(1.53)$ \\
\hline Years of financial loss in period 1980-85 & $-0.31(0.50)$ \\
\hline Number of pilots employed in thousands & 40 \\
\hline $\begin{array}{l}\text { Average years of service (primarily identifies commuter } \\
\text { airlines) }\end{array}$ & 0.41 \\
\hline $\mathrm{N}$ &
\end{tabular}

TABLE 3: Regression Results on the Percentage of Pilots in Each Group Who Believe That Initial Training Is Inadequate

\begin{tabular}{|l|c|}
\hline Explanatory Variable & Coefficient (Standard Error) \\
\hline Constant & $-6.07(9.37)$ \\
\hline Learning Curve Dummy Variables & $20.65(10.31)$ \\
\hline Captain & $5.98(8.57)$ \\
\hline First Officer & $1.43(0.44)$ \\
\hline Inter-Employer Variation & $5.45(1.16)$ \\
\hline Accidents/incidents per million departures & $7.72(1.57)$ \\
\hline Years of financial loss in period 1980-85 & $-1.56(0.60)$ \\
\hline Number of pilots employed in thousands & 40 \\
\hline $\begin{array}{l}\text { Average years of service (primarily identifies commuter } \\
\text { airlines) }\end{array}$ & 0.64 \\
\hline $\mathrm{N}$ &
\end{tabular}


TABLE 4: Regression Results on the Percentage of Pilots in Each Group Who Believe That the Maintenance / Airworthiness of Their Aircraft has Declined

\begin{tabular}{|l|c|}
\hline Explanatory Variable & Coefficient (Standard Error) \\
\hline Constant & $7.20(11.06)$ \\
\hline Learning Curve Dummy Variables & $5.47(12.18)$ \\
\hline Captain & $4.35(10.12)$ \\
\hline First Officer & $1.04(0.53)$ \\
\hline Inter-Employer Variation & $11.75(1.37)$ \\
\hline Accidents/incidents per million departures & $1.24(1.86)$ \\
\hline Years of financial loss in period 1980-85 & $-0.52(0.60)$ \\
\hline Number of pilots employed in thousands & 40 \\
\hline $\begin{array}{l}\text { Average years of service (primarily identifies commuter } \\
\text { airlines) }\end{array}$ & 0.74 \\
\hline $\mathrm{N}$ &
\end{tabular}

TABLE 5: Regression Results on the Percentage of Pilots in Each Group Who Believe That the Near Midair Collision Problem is Severe

\begin{tabular}{|c|c|}
\hline Explanatory Variable & Coefficient (Standard Error) \\
\hline Constant & $86.71(8.83)$ \\
\hline \multicolumn{2}{|l|}{ Inter-Employer Variation } \\
\hline Percentage of pilots based in California & $0.18(0.06)$ \\
\hline Percentage of wide body aircraft in fleet & $-0.41(0.19)$ \\
\hline Percentage of two-person cockpit aircraft in fleet & $-0.14(0.16)$ \\
\hline Percentage of automated aircraft in fleet & $-0.10(0.19)$ \\
\hline Percentage of Boeing 737 aircraft in fleet & $-0.11(0.22)$ \\
\hline Percentage of McDonnell Douglas DC9/MD80 aircraft in fleet & $-0.07(0.20)$ \\
\hline Commuter airline dummy variable & $0.69(17.23)$ \\
\hline $\mathrm{N}$ & 40 \\
\hline Corrected $\mathrm{R}^{2}$ & 0.17 \\
\hline
\end{tabular}

